\title{
School-based curriculum development as reflective practice: a case study in Hong Kong
}

\author{
S. Yuen ${ }^{1} \cdot$ H. Boulton ${ }^{1} \cdot$ T. Byrom ${ }^{1,2}$
}

Received: 29 July 2017 / Revised: 2 November 2017 / Accepted: 14 December 2017 / Published online: 19 February 2018

(C) The Author(s) 2018. This article is an open access publication

\begin{abstract}
This paper examines a school-based curriculum development (SBCD) experience in Hong Kong. Traditionally, curriculum change in Hong Kong has normally been bureaucratic with teachers' actions monitored. This qualitative case study investigates the lived experience of an SBCD practice. Semi-structured interviews were utilized to examine teachers' perceptions of the reflective SBCD experience in their school and what adaptations they had made when delivering the school-based materials. The findings identified that all teachers held a positive attitude towards this reflective approach to SBCD and emphasized artistry in their teaching practice. Teachers also exercised discretion in response to their students' level and interests when implementing the school-based curriculum at the classroom level. This research concludes that a reflective approach to curriculum planning with a bottom-up implementation can empower teachers reflecting their creativity, artistry, knowledge of the subject and related pedagogy, and knowledge of their students. The findings of this case study thus contrast sharply with previous research relating to Hong Kong government-led SBCD programs which focus more on meeting the requirements of the intended curriculum than on personalizing the curriculum to meet to learners' needs.
\end{abstract}

Keywords School-based curriculum development · Artistry in teaching $\cdot$ Hong Kong $\cdot$ Teacher attitude

\section{Introduction}

Knowles (1993, p.84) argues that effective teachers are ones who "act spontaneously and intuitively." This spontaneity is not a random process but, similar to Schön's (1983) reflectionin-action paradigm, means that teachers may not necessarily tell the theories behind their actions but what they do in the classroom encompasses their epistemology, experiences, and reflections on teaching. Likewise, school-based curriculum development (SBCD) can be a spontaneous and intuitive process that incorporates the curriculum developer's reflectionin-action. Here, SBCD can be tantamount to "writing as a method of inquiry" (Richardson 2000, p.962), which involves two dimensions:

\section{H. Boulton}

helen.boulton@ntu.ac.uk

1 Nottingham Trent University, Clifton Lane, Nottingham NG11 8NS, UK

2 Nottingham University, University Park, Nottingham NG7 2RD, UK
First, it directs us to understand ourselves reflexively as a person writing from a particular position at specific times. Second, it frees us from trying to write a single text in which everything is said at once to everyone.

Thus, a school-based curriculum (SBC), "written from a particular position at specific times" (ibid), stands out from the formal or intended curriculum that targets "everyone." While there are many well-established curriculum planning models available, Morris (1998) argued that there are no perfect models per se since the strengths of one model are often its weaknesses and vice versa. As such, he suggests that a curriculum developer should reflect on his or her own experience and at times on the socio-political context when developing an SBC.

The aim of this qualitative case study is to examine an SBCD experience in a Hong Kong secondary school that has taken a reflective approach to its curriculum planning in the English subject, thus contributing new knowledge to current dialogue globally. The Hong Kong school where this research was situated empowered an English teacher to write curriculum materials to support the delivery of one unit (Workplace Communication) which were then used by four 
English teachers. This is a novel approach for Hong Kong teachers who are more used to developing an SBC under the bureau's guidelines.

Using semi-structured interviews, this research sought to investigate (1) the teachers' attitude towards the SBCD practice in their school, (2) the adaptations made by the teachers when they implemented the SBC at the classroom level, and (3) how such a reflective practice in SBCD differs from other government-led SBCD schemes in previous case studies (c.f. Law 2001; Lo 1999) within the context of Hong Kong.

\section{Historical context of SBCD in Hong Kong}

Hong Kong's education system has been criticized as highly centralized. Teachers' actions were greatly affected by what the government, parents, and the school expect of them in the 1980s (Dickson and Cumming 1996; Morris 1997). Given the political and market forces in Hong Kong, teachers were viewed as technicians whose job was to transmit knowledge based on the intended curriculum without much regard for learners' differences. A statement by Hong Kong's Education Department (1992) recognized the need to encourage "schools to study and identify their own special needs and develop curricula to serve them" (cited in Morris and Adamson 2010, p.30). This was followed by several initiatives in the late 1990s that aimed to cater for learner diversity - school-based curriculum, project-based learning, and the target-oriented curriculum (c.f. Poon and Wong 2008).

The early launch of the School-based Curriculum Project Scheme (SBCPS) by the Education Department, however, did not liberate teachers from the highly centralized curriculum, as the government-led scheme aimed to reflect complex bureaucratic requirements such as requiring students to produce up-to-standard outputs for displays, rather than construct a school-focused curriculum that catered for the pupils' needs (Lo 1999; Wong 2002). Teachers were also required to attend training workshops outside their working hours to make sure that the SBC produced was in line with official regulations, and once they finished their curriculum development, they had to submit the documents for inspection (Lo 1999).

Following the education reforms in Hong Kong in the postcolonial era, the formal curriculum in Hong Kong was transformed from a highly centralized one to a more decentralized curriculum (Chan 2010; Law et al. 2010). The latter assumed that "teachers would become active professionals by renewing a teacher's role through the adoption of various government strategies such as guidelines, recommendations, and the use of school-based curriculum development" (Chan 2010, p.96). This assumption provided an opportunity for teachers to take an active, autonomous role in SBCD. In addition, schools may demonstrate their special characteristics via SBCD so that they can "stand out from the rest in the district" (Tan 2016, p.292). The Curriculum Development Council (CDC) has shown its resolution to promote $\mathrm{SBCD}$ by providing professional support to primary and secondary schools in the areas of curriculum planning, management, and leadership training (CDC 2001, p.112).

Following the government's promotion, "decentralization" has taken root over the past decade. This is evidenced by the CDC's (2014) observation that "[m]any schools have developed their own innovative school-based curriculum, learning and teaching strategies as well as measures to support student learning" (p.7). In its latest Basic Education Curriculum Guide (Primary 1-6) (CDC 2014), the CDC continued to encourage schools to plan their own curriculum by:

providing appropriate curriculum content and adopting suitable learning, teaching and assessment strategies to cater for students with different backgrounds, abilities and needs in the face of new learning needs brought about by the changes in society. (ibid., p.20)

In response to the initiative of SBCD, teachers are also encouraged to "become reflective practitioners" (ibid., p.22). However, the accountability mechanism taken by the government, which is described by Fok et al. (2006, p.52) as "hard measures," creates conditions where compliance with the formal curriculum and reforms is the only viable option. Although the 2014 document may have encouraged reflective practice among teachers, such practice is not without agendas as eight guiding principles for SBCD are explicitly outlined in the document, in particular:

3. A learner-focused approach should be used in curriculum development in order to make decisions on students' growth and learning in their best interests. Diversified learning, teaching and assessment strategies should be used to suit the different personalities, needs and interests of students....

6. Schools can design their school-based curriculum flexibly to cater for the needs of their students, as long as it satisfies the requirements of the central curriculum. (CDC 2014, p.15)

The above guiding principles specify the expectations, if not the agendas, of the CDC in the implementation of SBCD and thus can restrict artistry in teaching and even teachers' reflection to a certain extent. While the difference between SBCD as curriculum policy and SBCD as government-led support programs is noted, the latter placed strong emphasis on strategic support to implement the reforms with a highly targeted government funding source, whereas the SBCD described in the curriculum guides illustrated the ongoing 
process in schools to build up sustainability and teach artistry at school, panel, and classroom levels.

In the light of curriculum policy the "reflective approach" of SBCD is part of the intended or official curriculum (Curriculum Development Council 2014). However, in reality, teachers and curriculum leaders rarely move away from the guiding principles set in the central curriculum to avoid any adverse reports arising from school inspection by the government's inspectorate. As Kennedy et al. (2011) identified, two "hard policies" are (1) the Basic Competency Assessment, a standard test administered to primary students to evaluate if their academic performance in the school attain the bureau's standards, and (2) the External School Review, a quality assurance inspection conducted by the government officers to evaluate each school's performance based on the officially set performance indicators. These "hard policies" have prompted schools to "strive to comply with the requirements of the [performance indicators]" that are aligned with the reform agenda (ibid., p.51). SBCD, as part of the school policies, is inevitably injected with government-advocated initiatives that may not totally reflect the pupils' needs.

Thus, SBCD can result in becoming a vehicle of reforms rather than a reflective practice. However, it is acknowledged that the two may not be mutually exclusive as the curriculum documents do encourage teachers to be reflective practitioners. It should be noted that the way that the central curriculum is written in Hong Kong is different from the German Didaktik tradition, which

is centred on the forms of reasoning about teaching appropriate for an autonomous professional teacher who has complete freedom within the framework of the Lehrplan [or curriculum in English] to develop his or her own approaches to teaching.

(Westbury 2000, p.17)

In contrast, the curriculum guides in Hong Kong consistently remind teachers and schools what methods and approaches are deemed appropriate. For example, the latest draft of the English Language Education Key Learning Area Curriculum Guide (Primary 1-Secondary 6) states "Schools/ teachers are encouraged to..." appear in the document more than sixty times, placing teachers and school administrators in a passive position (CDC 2017).

However, it is recognized that there are changes taking place in Hong Kong. For example, the English Language Curriculum \& Assessment Guide (C\&A Guide) (S4-6) published by the $\mathrm{CDC}$, convened by the Education Bureau, and Hong Kong Examination and Assessment Authority (HKEAA) (2007) explicitly pointed out that "it is a good practice for teachers teaching the same year level to meet and decide on how the English Language curriculum may be adjusted for a particular class or group of learners" (CDC-
HKEAA, 2007,p102) and "they should feel free to select, adapt, or re-develop the suggested activities and materials" even though there are centrally available materials in supporting teachers to "deliver" the curriculum.

This research is therefore timely in looking at how these developments, recommended by the government in 2007 , have impacted on the respondents in this research. Although the aim to decentralize the curriculum shifts the accountability of planning and implementation for teachers, we argue that the bureaucratic control of SBCD has remained unchanged. SBCD continues, in some areas, to be a bureaucratic, "reform-driving" practice rather than supporting the teacher as a reflective practitioner.

\section{Research context}

The SBCD practice in the context of this case study differs from the bureaucratic practice as stated above. The primary aim of the former is not to produce an SBC that was aligned with the concerns of the intended curriculum but one that was based on teacher's reflective practice. The school under investigation is anonymized as TPSS. TPSS, funded by the government under Hong Kong's direct subsidy scheme (DSS), is a medium-sized secondary school with a student population of about 600 (Form 1-Form 6, 11-18 years of age). Different from other government-funded schools or aided schools, DSS schools manage their financial resources according to their own needs and therefore have more freedom to allocate their staff as appropriate.

Capitalizing on the greater freedom as a DSS school, TPSS deployed an English language teacher to develop a new curriculum, providing the freedom to plan activities that created an English-rich language environment for students to learn English. Four teachers were asked to deliver the curriculum. Consequently, the school had made a bold move in deploying more English teachers to develop school-based curricula and materials for different year groups.

At the start of the research, the authors identified the lack of a cohesive curriculum for a new Workplace Communication elective in Form 5 (equivalent to Year 11 in the UK). Workplace Communication is one of the electives that aims to serve the purpose of school-based assessment (SBA), in which "teachers are encouraged to customize the assessment according to students' characteristics, including language proficiency and personality, so that they could perform their best in a low-stress situation" (ibid., p.1). Thus, this unit of work has provided more autonomy for teachers to design their coursework, deliver the materials and assess their students. Another reason why this unit is selected is that SBCD appears to be less common in senior secondary. Curriculum flexibility is usually given to teachers when teaching subjects under junior secondary years. In senior years, teachers' teaching is 
mostly driven by the public examination syllabus because of the backwash from the external summative assessment (Kennedy et al. 2011). To reduce the negative blackwash effect, the government introduced the SBA in 2009, which formed part of the grade in the public examination, now known as the Hong Kong Diploma of Secondary Education (HKDSE) examination (Gao 2011).

It was therefore proposed to the school's subject panel to develop a new curriculum package. Based on the concept of "writing as a method of inquiry" (Richardson 2000, p.959), the SBC thus embodied opportunity for teachers to reflect as a learner and teacher of English, and the school-based materials (SBMs) were written specifically for the group of students in the school. The intention was to develop a curriculum which reflected the teacher's perception of teaching and learning English, as well as an analysis of students' level, interests, and needs. No pedagogical methods were specified in the SBC as teachers were also encouraged to adopt the same reflective approach to delivering the SBMs according to their students' needs and their preferred pedagogic approach. As this is the first elective in the English subject that has been written using the reflective approach, providing new freedom for the teachers involved, this unit of work was chosen as the focus of investigation in this study.

\section{Participants}

Four English teachers participated in the research. As in previous years, teachers set aside the last 4-6 weeks before the final school examination to teach this English elective and conducted the school-based assessment for their students, which formed part of the public examination grade. Since there were only four Form 5 teachers teaching the elective, they represented the total population in the case study. The sampling strategy used in this inquiry is, therefore, purposive sampling (Bryman 2012).

A brief profile of the four participants, using pseudonyms, is as follows:

Ms Sussie is a local teacher who was raised and educated in Hong Kong in her early years. Upon finishing her secondary school education, she continued her studies in the United States (USA), and graduated there with a major in Teaching English as a Second Language. She had 8 years of teaching experience by the time the research was conducted. At the time of the research, she was teaching the highest ability class.

Miss Joey was also raised and educated in Hong Kong, but chose to complete her first degree in the UK. She had 6 years of teaching experience by the time the research was conducted. At the time of the research, she was teaching a lower ability group.
Miss Tina completed her secondary and college education in Hong Kong. Compared to other teachers in the research, Miss Tina, who had only taught English for 3 years, had the least experience. At the time of the research, she was teaching a lower ability group.

Miss Mitchell was the only expat teacher in the research. Born in Malaysia but raised in Singapore, she completed her primary and secondary education in Singapore, and attended college in the USA. She was teaching the second highest ability group among the four classes under investigation and had 6 years of teaching experience.

The above brief introductions show that the teachers selected had only 3 to 8 years of teaching experience and thus not fully representative of all Hong Kong teachers in terms of teaching experience and curriculum development. Of the above participants, only Miss Joey and Miss Mitchell had previous experience in developing school-based materials for other levels. As in other case studies, the samples here may not provide a fair and wide representation. Thus, researchers must exercise caution when applying the findings to their own contexts.

\section{Research methods}

To understand the above teachers' lived experiences in implementing the SBC, the most effective method was to interview them (Berg and Lune 2012). In this case study, semi-structured interviews, with a prepared interview guide that included a number of questions (Roulston 2010), were used. The questions directed to the teachers were reflective in nature, and the topics were based on, but not limited to, the following themes:

a. Teaching strategies they usually use to teach English

b. Their views on the school-based curriculum (SBC) and the teaching materials

c. Pedagogy for teaching the SBC materials

The interviews, which lasted 30-45 min each, were then transcribed and analyzed thematically (Braun and Clarke 2006). One advantage of interviews and concomitant thematic analysis over surveys is that it provides flexibility for the participants to share their stories. Whereas, surveys are usually set by the researcher and the themes of the questions are predetermined (Babbie 2010) which can limit a participant's voice.

Thematic analysis allows researchers to identify, analyze, and report patterns according to the importance of the data presented by the participants (Braun and Clarke 2006). Thus, instead of setting pre-determined and assumptive themes for discussion, this research facilitated the 
emergence of socially constructed themes, using thematic analysis. The analysis of the interview data in this study followed the steps of thematic analysis outlined in Braun and Clarke (2006):

1. Sorting out the data-Since the data to be analyzed were derived from interviews with teachers, the interview scripts were examined in depth. The interviews, conducted with the four participants in the academic year 2012-13, were transcribed. While three participants preferred to use their mother tongueCantonese-for the interviews, their scripts were subsequently translated and analyzed in English. According to Berg and Lune (2012), there are many possible ways of transcribing interviews (e.g., Jefferson 2004). The simplest way is to include words, whereas others are transformed into punctuated sentences, using Jeffersonian conventions for instance, to show paralinguistic features, which help to analyze the speakers' emotions, verbal mannerism, tone of voice, and fluency. In this research, the former method of transcription that excludes paralinguistic features was adopted because it was irrelevant to examine the interviewees' speech production in their mother tongue.

2. Identifying the themes of interest-After transcribing the data, the researcher decoded the scripts using their own descriptors. A summary of the four interviews based on the descriptors was then created. The items that represented the four teachers' views on the SBC were highlighted and compared. These became the major theme of interest in this inquiry that is to explain the teachers' views on the SBC and highlight their preferences.

3. Further themes were selected from the scripts for further analysis and discussion, in particular the adaptations made by the teachers to the school-based materials.

4. Extracting data - data extract refers to individual coded data, which was identified within, and extracted from the data. Part of the data from the interviews was extracted to provide support for the developed themes, especially in terms of explaining the teachers' views on pedagogy.

Finally, the British Education Research Association's ethical guidelines were followed. The school and teachers involved have been anonymized. All teachers gave informed consent and understood their right to withdraw.

\section{Findings and discussion}

The section below is based on the findings uncovered via the thematic analysis. Themes were numbered in response to the three research questions specified in the introduction section.
Teachers show positive attitudes towards SBCD

Teachers in this study generally had positive attitudes and views of the school-based curriculum (SBC) designed for the English elective Workplace Communication and felt empowered to give constructive comments on how to improve the SBMs during the interviews.

Teachers in this inquiry all used the SBMs for their teaching on a voluntary basis and covered content to meet the needs of their students. Miss Joey and Miss Sussie, for example, explicitly mentioned in the interviews that they had completed the SBMs from cover to cover. Miss Tina also covered $90 \%$ of the content, but she skipped elements that provided a list of useful expressions and phrases used for a job advertisement to reflect the needs of her students. Miss Mitchell designed some extra assessment and lesson activities for her students, reflecting the needs of her students; these are discussed in greater detail below.

In this qualitative study, all four participants indicated their support for the SBCD in the researched school. All of them mentioned explicitly during the interviews that the curriculum developed by the school was able to cater for learner diversity:

Miss Mitchell: In our SBC, we gave them a passage that is similar to what they are going to write, so they are exposed to it. And after that, we teach step by step at different stages, like the introduction, the actual reason for such and such, reason one, reason two and then the conclusion. I think it's very good for weak students.

Miss Joey: [My views on the SBC] is positive because the things we produced can be manageable. The language we use in the SBC is easier, which caters for our students' level. The cost is also much lower because students don't need to buy a textbook. But the cost of [writing the materials] is very high.

Miss Tina: I gave my full support for the SBM. It was really developed in accordance with our students' levels.

Miss Sussie: I think the SBMs could save us the time used for planning how to teach writing. We only have to follow the materials, step by step. It really saves our preparation time. Our school has prepared something that the textbooks don't provide but that caters for our students' levels.

The above interview excerpts not only identify that teachers were positive about the school-based curriculum, but also point out the reasons for their support, such as planning for students' diversity, saving costs on textbooks for students, and reducing teachers' preparation time.

Fullan $(2008$, p.121) suggests that in order to teach the SBC successfully in each classroom, three Ps: personalization 
(addressing each child's learning needs), precision (tailoring the instruction to the needs without getting prescriptive), and professional learning (where each and every teacher learns every day) are essential. From the interview data, it can be seen that the first $\mathrm{P}$, personalization, has been addressed by all the participants. All of them used the SBMs not because they wanted to acquire the funding or to satisfy the government requirements, but because the materials were personalized to the needs of their learners.

\section{Teachers emphasize artistry in teaching}

Although teachers in this inquiry showed satisfaction with the SBMs, they also gave some constructive feedback. However, whilst the teaching materials contain imperfections, what the teachers were concerned about were not the way the SBMs were written, but how they brought the materials to life by tailoring the instruction, reflecting the second $\mathrm{P}$ identified by Fullan (2008) above.

Fullan (2008) suggests that by tailoring, or personalizing, learning embodies a sense of craftsmanship in teaching. Craftsmanship encompasses not only skills in making but also the artistic quality of workmanship, or "artistry." Teachers are similar to craftsmen in needing to craft their own teaching work based on the abilities of their students, thus placing teaching as a kind of artistry (Eisner 2005; Rubin 1983). Such artistry emphasizes the process of teaching in its "aesthetic, creative, dynamic, and indeterminate nature" (Lutzker 2012, p.53). Some teachers may love to experiment with innovations whereas others may pursue the traditional wisdom of craftsmanship. It was therefore different from teachers in the 1990s, in which teachers mostly followed the examination syllabus (Morris 1997).As participants suggest below, no matter how well the school-based curriculum is written or planned, it is always the teacher who brings it to life.

Miss Sussie: [when asked about what needs improving in this school-based materials developed by the researcher, she said:] Well, I don't think it's the problem of the materials. It's my teaching strategy that I need to adjust. To be honest, all the things needed are included in the school-based materials. Let's say it's a precious sword. You also need to know how to use it. Indeed, I need more time to plan for the lead-ins, the transitions between tasks and select tasks that are suitable for my students.

Miss Tina: As an English teacher, I also selectively choose the materials, and see which tasks are suitable for my group of students. I think you have provided us with the choices because there are different parts in the curriculum. Just depending on the school-based curriculum alone may not be enough to generate desired outcomes. We teachers also have to add some elements to lead to the outcomes.

Miss Mitchell: I think the purpose of education is, you still have to use the materials given to you, but you have to implement your own style of teaching, as well as make sure that you are enticing the kids to learn.

Miss Joey: I don't have a preference [for what materials to be used] because I [am empowered] to adapt to the materials - whether they are easy or difficult. Our students need extra help. What's more important is we need to observe the student's learning progress in the first few lessons. Then we need to adapt to the materials on hand. It's impossible that you could predict beforehand the students' ability and interests and create a course pack that's perfect.

What the above teachers emphasize is skill and discernment: teachers need to analyze the features of the materials at hand before crafting them for their individual classrooms, leading to developing artistry. It also goes with the art of Didaktik in German education, where the state curriculum "can only become educative as it is interpreted and given life by teachers" (Westbury 2000, p.17). Here, teachers' interpretation can be attributed to the other influencing contexts, for example curriculum reform and past experiences, and not necessarily from the specific SBCD experience itself.

Returning to Fullan's (2008, p.121) concept of "precision," he does not equate "precision" with following the curriculum in a strict manner but "tailoring the instruction to the needs without getting prescriptive." In SBCD, it is therefore important to devise a curriculum with this type of precision in Hong Kong. Teachers should be given room to practice artistry in their classrooms and make good decisions in the classroom.

The way that the SBMs are delivered should be at the teachers' discretion, based on the teachers' professionalism and knowledge of their learners. Nevertheless, there seemed to be little place for teachers' decisions as indicated in the expert-designed curriculum guides developed by the Hong Kong government. This was identified by Zeichner (1994, p.10) as "a general lack of respect for the craft knowledge of good teachers in the educational research establishment which has attempted to define a so-called 'knowledge base' for teaching minus the voices of teachers".

Not only in Hong Kong, but also in other educational settings, frontline teachers are not always given the respect and autonomy they deserve. Murray (2016), for instance, observes that many language teachers working in higher education frequently feel undervalued by mainstream academic seniors and that their expertise is often overlooked. Likewise, in Hong Kong during the earlier years of reform, teachers' teaching practice was criticized in the reform documents as "fragmented and overcrowded; lacking coherence; emphasizing rote memorization ..." (Morris et al. 2003, pp.81-82). As a result, a number of educational initiatives and teaching 
methods have been introduced such as the recent emphasis of e-learning, self-directed learning, language across the curriculum, reading across the curriculum, and assessment for/as learning (CDC 2017) to help teachers rectify their malpractice. These newly introduced initiatives are usually turned into what Kennedy et al. (2011, p.52) call "hard measures," progressively forcing frontline teachers to comply indiscriminately. If teachers are expected to be "reflective practitioners" (CDC 2014, p.22), we would argue the CDC should be encouraged to change its curriculum guides "without getting prescriptive" (Fullan 2008, p.121) and allow greater teacher autonomy by not only encouraging teachers to "feel free to select, adapt, or re-develop the suggested activities and materials" (CDC 2007, p.102) but also liberating the teachers from the use of advocated approaches or guidelines whether it is e-learning or self-directed learning.

The following subsection demonstrates the voices of teachers by highlighting the "craft knowledge" (Zeichner 1994, p.10) of two teachers in this case study. These two participants represent extreme examples of how teachers adapt SBMs to cater for their pupils' needs.

\section{Teachers' adaptation based on students' needs}

As mentioned in the previous section, teachers in this study all stressed how they brought the SBMs to life by tailoring their instructions to suit the pupils' needs. The interview data presented here demonstrate that teachers teach according to the group of students in each classroom.

One example in this inquiry was Miss Mitchell, who was teaching a higher ability form. At the time of this research, she was also teaching a lower-form class (Year 7). Despite her interest in project-based learning pedagogy, she admitted that it was difficult to do so in her lower-form class where the pupils were of lower ability:

Miss Mitchell: I tried to implement it into the [weaker ability group]. But it's very hard as the kids' level of English is very low. So you have to basically give them more input.

However, teaching students of higher ability in this case study allows her to incorporate project-based learning into the SBC:

Miss Mitchell: [11] So, [for this higher ability group], they were supposed to do a project and after this project, I put in my own questions... it was in the hope that, through their experience - they have done on the project, they would realize the kind of jobs that would be required of them.
Using Flint and Peim's (2012, p.35) definition of a "liberal classroom," Miss Mitchell was teaching her students to be reflective, self-directing, and self-managing through the introduction of a creative project into her class. The example presented by Miss Mitchell evidences that teachers do make adaptations in different contexts.

Another example is Miss Joey. Recalling her learning experiences in her secondary school, she mentioned that she received minimal help from her English teacher and had to complete all the exercises assigned by the teacher on her own. However, teaching the weakest class in the case study, Miss Joey said candidly that she had developed comprehensive scaffolding and step-by-step guides for her group of students:

Miss Joey: Maybe students don't have self-learning skills these days. Their ability was very low, so you have to prepare all the things and stuff them into their brain. That's why you have to spend time looking for materials, organizing them so that students can memorize the things easier and regurgitate the things again. So teachers have to make lots of preparations.

Whilst the SBMs already included a list of job titles from different categories, some of her students found them incompatible to their interest. By personalizing her teaching for her students, Miss Joey catered for her all students' needs and made greater effort in developing materials for them:

Miss Joey:... Some boys in my class wanted to be professional football players, and even a fire fighter. These jobs are not mentioned in the course pack, but they could think of them. But they didn't know how to [write about] these jobs. Then I had to teach them to search on the government websites to find out what requirements or levels these jobs required. Sometimes, I needed to teach them how to read the websites. ...

... Then I had to search the information and reorganize the materials for them. But since you have developed the frame such as the job title, requirements, skills etc. I just had to follow this pattern and look for relevant information.

The two examples above indicate that teachers adopted various strategies according to the group of students they had, be they learner-centered as in Miss Mitchell's case or teacher-guided as in Miss Joey's case. The teachers were able to make adaptations in response to different constraints and contexts. By the same token, we argue that SBC developers 
should continue to reflect on the contextual constraints when planning the curriculum in Hong Kong so that teachers are encouraged to move away from being described as "technicians" (Morris and Adamson 2010, p.30). This is supported by the CDC in the central curriculum guide which encourages teachers "to employ his/her subject knowledge, professional skills, and understanding of the learners to select and use appropriate methods to help them to work towards the Learning Targets and Objectives [stated in the curriculum guide]" (CDC, p.102). However, the word "appropriate" may imply that schools/teachers are required to adhere to certain guiding principles, including to:

... provide access to a rich variety of learning experiences, a balanced and coherent school-based curriculum emphasising the active roles of learners in the learning process should be developed. (ibid, p. 51)

However, not all the guiding principles should be applicable as in Miss Joey's class in which students lacked the motivation to take an active role in their learning. Miss Joey therefore adopted a more teacher-centered approach in her teaching and kept encouraging her students not to give up.

\section{Teacher-initiated program vs government-led program}

The findings indicated above contrast sharply with the previous case study conducted in early years about the SBCD programs initiated by the Hong Kong government (e.g., Law 2001; Lo 1999). To begin with, the benefits of SBCD mentioned by the teachers in this research such as catering for pupils' needs and saving time for lesson preparation were absent in the government-initiated programs. In Lo's (1999) research about the government-initiated SBCPS for example, teachers were strictly scrutinized during the process of curriculum planning, and had to attend workshops organized by the Education Department after a long day of work to make sure that the materials they produced addressed the concerns of the intended curriculum. In addition, teachers were passionate in encouraging students to produce outputs for bureau's inspection, and thus unable to teach according to the students' levels and individual learning needs. Although the government-led SBCD programs were finally implemented at the classroom level, the teachers merely put it up as a one-off initiative in order to secure the funding. Lo (1999, p.463), therefore, concludes:

... the nature of the [SBCPS] was promoted as a means to pursue the goals commonly associated with SBCD, namely the identification and satisfaction of pupils' needs, and of teachers' involvement in curriculum development. In reality, the scheme was highly centralized and resulted in the Education Department maintaining control of the process and products of the scheme. It is therefore, a bureaucratic version of SBCD which stressed the one-off production of classroom materials.

Other research (Law 2001) into the same governmentinitiated scheme in a different setting also showcased scenarios of such highly centralized decentralization practice. Teachers, as shown in Law's study (2001), were required to follow the teaching activities stated in the SBC. One teacher found it incompatible with his own teaching philosophy and opted to withdraw from the program. The episode in Law's study thus differed from the reflective approach shown in the case study as in the latter, teachers were able to adapt to the materials in response to students' level and learning needs. Teaching should be treated as an artful practice rather than a technical procedure.

Teachers should be given autonomy to tailor the materials for the needs of their students. Education should not be a bureaucratic practice, described by Weber $(1978, p .223)$ as a measure "superior to any other form in precision, in stability, in the stringency of its discipline, and in its reliability." Teaching differs from doing experiments. In the latter, you need to ensure precision, stability, and reliability by strictly following all the steps in order to generate the same experiment results. The implementation of a curriculum written according to the reflective approach is a different narrative, as Eisner (2002, p.381) states:

Those interested in curriculum matters and working with teachers began to recognize that the conditions teachers addressed were each distinctive. As a result, abstract theory would be of limited value. Each child needed to be known individually ... each situation ... was unique. It was a grasp of these distinctive features that the teachers needed to make good decisions in the classroom.

Following the above studies related to governmentinitiated programs, there have been sporadic case studies over the past decade about medium- to large-scale SBCD projects initiated by local universities, bureaucrats, and joint schools (Lam and Yeung 2010), as well as research relating to SBCD leadership (Lo 2008). Although there has been evidence showing that the government has taken the role of facilitator in the SBCD initiative in recent years, its supportive means is criticized as a "quality assurance measure in disguise" (Lam and Yeung 2010, p.78). Meanwhile, the Education Bureau continues to view SBCD as the vehicle of reform, as indicated in its webpage: 
In developing a school-based curriculum, the process and the result are equally important. In other words, the aim is to promote professional growth in teachers and development of school, so that students can learn more effectively. With school as the base of education reforms, teachers and the principal make decisions regarding the curriculum development through careful thought, including curriculum objectives, curriculum content, design of teaching and learning activities and teaching and learning materials, and curriculum evaluation.

(Education Bureau 2012, n.p.)

Thus, the Education Bureau in attempting to promote professional growth in teachers and development of a school via the SBCD initiative. However, if professional growth was to mean, as in Lo's case (1999), attending workshops and learning how to incorporate e-learning, self-directed learning, or other government-advocated initiatives into the school-based curriculum, SBCD would only turn into ad hoc projects aimed to satisfying the government's reform rather than students' needs. Here, we do not argue the effectiveness of these workshops, rather that schools should not be regarded as the "base of reforms," which should make every effort to put forward the government initiatives via SBCD. While further research is needed for the effectiveness of this type of reform-steering SBCD practice on students and teachers, the Education Bureau should consider advocating a more reflective approach to SBCD planning. The difference between the two is that the former is initiated by external force, whereas the latter is based on internal needs. In other words, SBCD should be a bottomup initiative reflecting the teachers' experience, philosophies, and socio-political constraints rather than a top-down measure, in which the government or the even school itself super-imposes centrally planned curriculum framework and officially advocated methods upon the school-based curriculum. This reflects Chiu Chi-shing's (2017), a local scholar specializing in school improvement, view when he warned

During the early years of curriculum reforms, the four major initiatives were identified as project-based learning, promotion of reading, moral and civic education and information technology. These initiatives did not come about based on the school's needs or on the school improvement data. Such [externally driven] initiatives can hardly be internalised or implemented sustainably by the teaching team. (cited in Chiu's webpage, 2017, n.p.)

The SBCD project investigated in this case study is now in its fourth year of implementation. The content has been reviewed and evaluated with only minor change, thus reflecting the sustainability of bottom-up curriculum change based on internal needs.
Finally, future research should be undertaken to find out what leads teachers to turn to "centralized" curricula, schemes of work, and materials in their SBCD designs. The answer may lie in many factors, e.g., individual school culture and leadership, reforms accountability framework, lack of coordination or coherence between different policies and strategies in reforms, assessment requirements, lack of experience in teaching a new curriculum, and lack of time and space to develop new school-based curriculum.

\section{Conclusion}

Participants in this case study held a positive attitude towards the SBC, which was developed and implemented with regard to the teachers' reflective practice rather than the official rigidity which has been the tradition in Hong Kong. In contrast with previous research on government-led programs in Hong Kong (Law 2001; Lo 1999), this case study illustrated a bottom-up, teacher-initiated effort that fully embodied the spirit of SBCD, namely identification of learners' needs and greater teachers' involvement (Skilbeck 1984). Other benefits of SBCD were also unearthed in the interviews such as saving teachers' preparation time and reducing the cost of textbooks for students. In addition, the SBCD program launched in the school empowered teachers to exercise their discretion and hence they could make adaptations to the SBC according to their students' needs, thus introducing a new pedagogic approach in Hong Kong's DSS schools.

The contrast between this case study and the governmentinitiated SBCD schemes indicates that implementation which aims to satisfy complex bureaucratic requirements can never lead to the authentic purpose of school-based curriculum (Wong 2002). Wong worked with seven primary schools in Hong Kong to design a model for SBSCD, reflecting the unique characteristics of the schools involved and concluded "[e]ach school has displayed many different or unique characteristics; therefore a [School-based Science Curriculum Development] plan is tailored-made for schools based on the needs of the students" (ibid, p.16).

As predicted by Weber (1978, p.225), modern society is usually dominated by bureaucratic measures that attempt to ensure that everybody follows the same expert-claimed norms in order to achieve the same "desired" results:

...Without hatred or passion, and hence without affection or enthusiasm. The dominant norms are concepts of straightforward duty without regard to personal considerations. Everyone is subject to formal equality of treatment; that is, everyone in the same empirical situation. This is the spirit in which the ideal official conducts his office. 
Weber's prediction is prevalent throughout the official curriculum documents in Hong Kong, in which one can find various models and expert-designed terms such as "learning to learn," "target-oriented," "integrated curriculum," and "catering to learners' diversity" in the official guides (c.f. CDC 2007). We do not argue whether these models and concepts are appropriate or not. However, if teachers just blindly follow these concepts without "personal consideration" or reflecting on their past experiences and beliefs, they would only deliver a rigid curriculum irrelevant to the learning needs of pupils and the context. Using Weber's term, teachers would end up teaching " $[w]$ ithout hatred or passion, and hence without affection or enthusiasm" (Weber 1978, p.225).

What is missing in the government documents and the government-led initiatives in Hong Kong is, therefore, opportunity for personalization, or more accurately teachers' beliefs, reflections, and particularly passion. Passion, as described concretely by Day (2004, p.12), as "the qualities that effective teachers display in everyday social interactions." Such qualities include, but are not limited to:

listening to what students say, being close rather than distant, having a good sense of playfulness, humour, encouraging students to learn in different ways, relating learning to experience, encouraging students to take responsibility for their own learning, maintaining an organised classroom environment, being knowledgeable about their subject, creating learning environments that engage students and stimulate in them an excitement to learn. (ibid)

These qualities are evidently vested in the participants. Without passion, Miss Joey would not have prepared additional materials for her students in every learning task she delivered. Without passion, Miss Mitchell would not have designed another project for her students.

SBCD in Hong Kong's DSS schools should not be one-size-fits-all bureaucratic practice that carries no soul. Nor should it be reduced to a vehicle of reforms. Teachers should be allowed to exercise discretion when necessary, and always encouraged to act "spontaneously and intuitively but reflect prior to and after their actions" (Knowles 1993, p.84). However, before a fully reflective approach is achieved in SBCD, curriculum developers globally may continue to face different limitations such as the backwash of the public examinations, the accountability measures taken to supervise the DSS schools, and the prerequisites-vested definition of SBCD in the official curriculum documents.
Open Access This article is distributed under the terms of the Creative Commons Attribution 4.0 International License (http:// creativecommons.org/licenses/by/4.0/), which permits unrestricted use, distribution, and reproduction in any medium, provided you give appropriate credit to the original author(s) and the source, provide a link to the Creative Commons license, and indicate if changes were made.

\section{References}

Babbie, E. (2010). The practice of social research. Wadsworth: Cengage Learning.

Berg, B. L., \& Lune, H. (2012). Qualitative research methods for the social sciences. New York: Pearson Education Limited.

Braun, V., \& Clarke, V. (2006). Using thematic analysis in psychology. Qual Res Psychol, 3(2), 77-101.

Bryman, A. (2012). Social research methods (4th ed.). New York: Oxford University Press.

Chan, J. K. (2010). Teachers' responses to curriculum policy implementation: colonial constraints for curriculum reform. Educ Res Policy Prac, 9(2), 93-106.

Chiu, C. S. (2017). Chiu Chi-Shing talks about education and other issues. Available at: https://chiued.blogspot.hk/. Accessed 15/10/ 2017.

Curriculum Development Council. (2001). Learning to learn: lifelong learning and whole-person development. Hong Kong: The Printing Department.

Curriculum Development Council. (2007). English language curriculum and assessment guide (secondary 4-6). Hong Kong: Hong Kong Government.

Curriculum Development Council. (2014). Basic education curriculum guide - to sustain, deepen and focus on learning to learn (primary 1-6). Hong Kong: The Printing Department.

Curriculum Development Council. (2017). English language education key learning area curriculum guide (Primary 1 -Secondary 6) Draft May 2017. Available at: http://www.edb.gov.hk/attachment/en/ curriculum-development/renewal/ELE/ELE_KLACG_eng_draft 2017 05.pdf. Accessed 14/10/2017.

Day, C. (2004). A passion for teaching. New York: RoutledgeFalmer.

Dickson, P., \& Cumming, A. (Eds.). (1996). Profiles of language education in 25 countries. Slough: NFER.

Education Bureau. (2012). Definition of school-based curriculum development [online]. http://www.edb.gov.hk/en/edu-system/primarysecondary/applicable-to-primary-secondary/sbss/school-basedcurriculum-secondary/principle/definition.html. Assessed 20 May 2017.

Eisner, E. W. (2002). From episteme to phronesis to artistry in the study and improvement of teaching. Teach Teach Educ, 18(4), 375-385.

Eisner, E. W. (2005). Reimagining schools: the selected works of Elliot Eisner. New York: Routledge.

Flint, K. J., \& Peim, N. (2012). Rethinking the education improvement agenda: a critical philosophical approach. Edinburgh: A \& C Black.

Fok, P. K., Kennedy, K. J., Chan, K. S. J., \& Yu, W. M. (2006). Integrating assessment of learning and assessment for learning in Hong Kong public examinations: rationales and realities of introducing school-based assessment. Paper presented at the 32nd Annual Conference of International Association for Educational Assessment: Assessment in an Era of Rapid Change: Innovations and Best Practices, Singapore.

Fullan, M. (2008). Curriculum implementation and sustainability. In F. Michael Connelly, M. F. He, \& J. Phillion (Eds.), The sage handbook of curriculum and instruction (pp. 113-122). Thousand Oaks: Sage. 
Gao, M. (2011). School-based assessment in Hong Kong: impact on students' attitudes and anxiety. HKU Theses Online (HKUTO).

Hong Kong Education Department (1992) In P. Morris, \& B. Adamson (Eds.), Curriculum, schooling and society in Hong Kong. Hong Kong: Hong Kong University Press.

Jefferson, G. (2004). Glossary of transcript symbols with an introduction. Pragmatics and Beyond New Series, 125, 13-34.

Kennedy, K. J., Chan, J. K., \& Fok, P. K. (2011). Holding policy-makers to account: exploring 'soft' and 'hard' policy and the implications for curriculum reform. Lond Rev Educ, 9(1), 41-54.

Knowles, J. G. (1993). Life-history accounts as mirrors: a practical avenue for the conceptualization of reflection in teacher education. In J. Calderhead \& P. Gates (Eds.), Conceptualizing reflection in teacher development (pp. 70-92). London: The Falmer Press.

Lam, C. C., \& Yeung, S. Y. (2010). School-based curriculum development in Hong Kong. In E. H. F. Law \& N. Nieveen (Eds.), Schools as curriculum agencies (pp. 61-82). Taipei: Sense Publishers.

Law, E. (2001). Impacts of a school-based curriculum project on teachers and students: a Hong Kong case study. In M. Brennan (Ed.), Education futures \& new citizenships: proceedings of the 10th national biennial conference of the Australian curriculum studies association (Vol. 1, pp. 335-355). Canberra: Australian Curriculum Studies Association.

Law, E. H. F \& Nieveen, N. (2010). Schools as curriculum agencies. Taipei: Sense Publishers.

Lo, Y. C. (1999). School-based curriculum development: the Hong Kong experience. Curric J, 10(3), 419-442.

Lo, Y. C. (2008). An initial investigation of curriculum leadership in Hong Kong primary school. In Y. C. Lo \& M. S. Yung (Eds.), School curriculum reforms and teachers' professional development: cases in Mainland China, Hong Kong and Macau [in Chinese] (pp. 142-155). Hong Kong: Association of Childhood Education International.

Lutzker, P. (2012). Developing artistry in teaching: new approaches to teacher education. RoSE-Research on Steiner Education. Available at http://www.rosejourn.com/index.php/rose/article/viewFile/96/ 122. Accessed 03 Mar 2017.

Morris, P. (1997). School knowledge, the state and the market: an analysis of the Hong Kong secondary school curriculum. J Curric Stud, 29(3), 329-349.
Morris, P. (1998). The Hong Kong school curriculum — development, issues and policies (2nd ed.). Hong Kong: Hong Kong University Press.

Morris, P., \& Adamson, B. (2010). Curriculum, schooling and society in Hong Kong. Hong Kong: Hong Kong University Press.

Morris, P., Chan, K. K., \& Lo, M. L. (2003). Changing primary schools in Hong Kong: perspectives on policy and its impact. In P. Stimpson, P. Morris, Y. Fung, \& R. Carr (Eds.), Curriculum, learning and assessment: the Hong Kong experience (1st ed., pp. 77-96). Hong Kong: Open University of Hong Kong Press.

Murray, N. (2016). An academic literacies argument for decentralizing EAP provision. ELT J, 70(4), 435-443.

Poon, A. Y., \& Wong, Y. (2008). Policy changes and impact of the education reform in Hong Kong. Journal of Taiwan Normal University: Education, 53(3), 47-65.

Richardson, L. (2000). Writing: a method of inquiry. In N. K. Denzin \& Y. S. Lincoln (Eds.), Handbook of qualitative research (2nd ed., pp. 923-948). Thousand Oaks: Sage.

Roulston, K. (2010). Reflective interviewing: a guide to theory and practice. New York: Sage.

Rubin, L. (1983). Artistry in teaching. Educ Leadersh, 40(4), 44-49.

Schön, D. A. (1983). The reflective practitioner: how professionals think in action. New York: Basic books.

Skilbeck, M. (1984). School-based curriculum development. London: Harper \& Row Ltd.

Tan, C. (2016). Teacher agency and school-based curriculum in China's non-elite schools. $J$ Educ Chang, 17, 287-302.

Weber, M. (1978). Economy and society: an outline of interpretive sociology. London: University of California Press.

Westbury, I. (2000). Teaching as a reflective practice: what might didaktik teach curriculum? In I. Westbury, S. Hopmann, \& K. Riquarts (Eds.), Teaching as a reflective practice the German didaktik tradition (pp. 15-39). New Jersey: Lawrence Erlbaum Associates.

Wong, T. T. S. (2002). A case study of school-based science curriculum development: overview of project approach and process of implementation. [Online] Asia-Pacific Forum on Science Learning and Teaching. Available at http://www.eduhk.hk. Accessed 4 Sept 2016.

Zeichner, K. M. (1994). Research on teacher thinking and different views of reflective practice in teaching and teacher education. In I. Carlgren, G. Handal, \& S. Vaage (Eds.), Teachers' minds and actions: research on teachers' thinking and practice (1st ed., pp. 9-27). Bristol: Falmer Press London. 